Araştırma Makalesi / Research Article

Endüstri Mühendisliği /

Industrial Engineering

DOI: $10.21597 /$ jist.579958
Iğdır Üniversitesi Fen Bilimleri Enstitüsü Dergisi, 9(4): 2002-2008, 2019

Journal of the Institute of Science and Technology, 9(4): 2002-2008, 2019

\title{
A New Mathematical Model for Assembly Line Worker Assignment and Balancing
}

\section{Hamid YILMAZ ${ }^{1 *}$, Yunus DEMIR ${ }^{2}$}

ABSTRACT: Aim of assembly line balancing is to assign the product parts to the workstations that constitute the assembly line. Worker assignment problem is a new problem variety in assembly lines that typically is met in different situations in which the workforce is not homogeneous. This problem is different from the well-known simple assembly line balancing problem from the view point of task execution times of nonhomogeneous workers. In this paper, we introduce a new mathematical formulation with objective function to minimize the cycle time for the assembly line worker assignment and balancing problem (ALWABP). GUROBI solver is used for the problem solution. The mathematical model is examined by using a standard test problem set. As a result of the experiments, it is observed that the proposed mathematical model is more effective in terms of solution quality and CPU time than the current mathematical method.

Keywords: Worker assignment, Assembly line balancing, Mathematical modelling

\footnotetext{
${ }^{1}$ Hamid YILMAZ (Orcid ID: 0000-0003-0852-4119), Bayburt University, Engineering Faculty, Industrial Engineering Department, 69000 Bayburt, Turkey

2 Yunus DEMIR (Orcid ID: 0000-0002-3874-5388), Bursa Technical University, Faculty of Engineering and Natural Sciences, Industrial Engineering Department, 16330 Bursa, Turkey

*Sorumlu Yazar / Corresponding Author: Hamid YILMAZ, e-mail: hamidyilmaz@gmail.com
} 


\section{INTRODUCTION}

An assembly line balancing system is a mass production system that is used in standardized product(s), such as white appliances or automobiles. In assembly lines, it usually consists of several stations that are linked to each one by a handling system to move the unfinished products from one station to the next one. Small assembly parts of products are called tasks in assembly line balancing. Tasks are executed by robots, workers or both. Also, these tasks include precedence relations that affect assembly constraints in workstation assignments (e.g light bulbs are assembled before assembly of headlight).

Basic form of a line balancing is known as simple assembly line balancing problem (SALBP). In this problem, objective and basic assignment constraints are taken in consideration (Scholl and Becker, 2006). Also, alternative mathematical models known as General Assembly Line Balancing Problem are presented in the literature (Battaïa and Dolgui 2013).

The basic concept of the problem presented in this paper is a special condition of SALBP by incorporating heterogeneity among workers on assembly duration of tasks. This problem is called in the literature as assembly line worker assignment and balancing problem (ALWABP). In ALWABP, assembly time of each task differ due to operator who execute the task, and some task(s) is incompatible for some worker(s). Station and worker assignment procedures are observed in ALWABP. Because of this reason, ALWABP is NP-hard in nature (Pereira, 2018).

In the literature, minimizing the cycle time is a common aim for the ALWBP and it is called ALWBP-2. In this study, ALWBP-2 is discussed with a new mathematical model. For the first time, Miralles et al. (2007), presented Assembly line worker assignment and balancing problem. In that study, they proposed assembly line balancing worker assignment and balancing problem that assigning tasks to workers with consideration of work capacity and respecting the constraints of each private individual.

Benchmark data sets (Roszieg, Heskia, Tonge, Wee-Mag) for assembly line worker assignment and balancing problem type- 2 are proposed by Chaves et al. (2007).

Miralles et al. (2008), presented a branch and bound algorithm with different parameters and search strategies, with mathematical model formulation. Also branch and bound algorithm based heuristic is proposed for large test instances to improve the solution quality.

Chaves et al. (2009), proposed a hybrid method clustering search to solve the ALWABP. Computational results are presented to demonstrate the efficacy of the method.

A tabu search metaheuristic developed by Moreira and Costa (2009) for assembly worker assignment and balancing problem. The presented method is flexible, simple, accurate and fast. They compare the method with other solution methods available in the literature and the results show that the tabu algorithm outperforms other methods.

Blum and Miralles (2011), introduced beam search algorithm with the objective of minimizing the cycle time for solving the ALWABP-2 for fixed number of station. The algorithm is enhanced method for the ALWABP-2 based on experimental results.

Moreiro et al. (2012), proposed simple heuristics for the ALWABP. A constructive heuristic framework is developed in their study. The results show that the heuristic is fast and achieved good solution results.

A genetic algorithm developed by Mutlu et al. (2013) to solve assembly line worker assignment and balancing problem, and three search method are adopted. Performance of iterative genetic algorithm is compared with metaheuristic approaches in the literature with benchmark test problems. The effectiveness and robustness of the method is shown with large set of benchmark test problems. 
A branch and bound algorithm is developed by Vila and Pereira (2014), which uses the lower bounds, to solve the ALWABP. Experiments show that the proposed algorithm is the best performing solution method in the literature.

Polat et al. (2016), proposed a two-phase variable neighbourhood search algorithm to solve the type 2 ALWABP problem. The performance of the proposed algorithm is showed on wellknown benchmark instances.

Pereira (2018), consider min max regret assembly line and worker assignment balancing problem. Also, Akyol and Baykasoğlu (2019), proposed a new type of ALWABP which considers ergonomic risks, and they called the problem ErgoALWABP. A solution procedure is enhanced to the problem with the multiple-rule based constructive randomized search.

Although many heuristic methods are applied to ALWABP, as seen in the literature proposed mathematical models are limited. In this paper, we introduce a new mathematical formulation with objective function to minimize the cycle time for ALWABP.

\section{MATERIALS AND METHODS}

\section{Existing Mathematical Model}

Existing model in the literature was formulated by Miralles et al. (2008) and this model is written as below:

$i, j$ : index of task

$h$ : index of worker

$s$ : index of workstation

$A$ : set for tasks

$B$ : worker set

$O$ : workstation set

$c$ : cycle time

$t_{h i}$ : i. task assembly time for h. worker when assembly it

$I P_{i:}$ : immediate predecessor set for $i$

$x_{\text {shi: }}: 1$; when $i$. task is assigned to operator $h$ in station $s$, otherwise 0

$y_{s h}: 1$; when operator $h$ is assigned to station $s$.
Min $c$

$\sum_{h \in B} \sum_{s \in O} x_{s h i}=1, \forall i \in A$,

$\sum_{s \in O} y_{s h} \leq 1, \forall h \in B$,

$\sum_{h \in B} y_{s h} \leq 1, \forall s \in O$,

$\sum_{h \in B} \sum_{s \in O} s . x_{s h i} \leq \sum_{h \in B} \sum_{s \in O} s . x_{s h j} 1, \forall i ; j / i \in I P_{j}$

$\sum_{i \in A} t_{h i} \cdot x_{s h i} \leq c, \forall h \in B, \forall s \in O$,

$\sum_{i \in A} x_{s h i} \leq M \cdot y_{s h}, \forall h \in B, \forall s \in O$,

$y_{s h} \in[0,1], x_{s h i} \in[0,1], \forall h \in B, \forall s \in O, i \in A$

The aim of objective function is to minimize cycle time (1). Constraint (2) ensures tasks are assigned to worker in one single workstation. Constraint (3) and (4) provide that in every station there will be a worker, and every worker will be assigned to one workstation. Constraint (5) is precedence relations of tasks. Constraints (6) and (7) ensure assigning more than 1 task in a cycle time (c). Constraint (8) is binary variables in model.

\section{Proposed Mathematical Model}

Mathematical formulation that was proposed by us can be written as below:

$i, h$ : index of task

$t$ : index of worker

$j$ : index of workstation

I: task set

$T$ : worker set

$J$ : workstation set

$c$ : cycle time

$t_{i t}$ : i. task assembly time for $\mathrm{t}$. worker when assembly it

$I P_{i}$ : immediate predecessor ser for $i$

$x_{i j}: 1$; when task $i$ is assigned to workstation $j$,

otherwise 0

$y_{j t}: 1$; when worker $t$ is assigned to workstation $j$. 
Min $c$

$\sum_{j \in J} x_{i j}=1, \forall i \in I$,

$\sum_{t \in T} y_{j t} \leq 1, \forall j \in J$

$\sum_{j \in J} y_{t j} \leq 1, \forall s \in W$,

$\sum_{j \in J} x_{i j} \leq \sum_{j \in J} x_{h j} \forall i \in I, \forall h \in H$

$\sum_{i \in I} x_{i j} \leq M . \sum_{t \in T} y_{j t} \forall j \in J$

$\sum_{i \in I}\left(x_{i j}+y_{j t}-1\right) \cdot t_{i j} \leq c, \forall j \in J, \forall t \in T$,

$y_{j t} \in[0,1], x_{i j} \in[0,1], \forall i \in I, \forall j \in J, \forall t \in T$

The aim of objective function is to minimize cycle time (9). Constraint (10) ensures tasks are assigned to one single workstation. Constraint (11) and (12) provide that a task will be assign a worker, and an assigned worker will have tasks to execute. Constraint (13) is precedence relations of tasks. Constraint (14) ensures if task or tasks are assigned to a workstation, a worker will assign to that workstation. Constraint (15) ensure assigning more than 1 task in a cycle time. Constraint (16) is binary variables in model.

\section{RESULTS AND DISCUSSION}

In computational experiment section, we proposed computational study with mathematical models. Test problem data is generated from single assembly line balancing problem data set proposed by Chaves et al. (2007). In this data, 320 test problems are grouped into four families (Wee-Mag, Tonge, Roszieg and Heskia). There are 80 test problems in each of the data families. In test problems, each task groups contains 10 test instances and totally 32 test problems are grouped.

The models were run in Microsoft Visual Studio 2015 C\# with the solver GUROBI 8.0. The test instances were run on an Intel-Core-i5-3.00 $\mathrm{GHz}$ processor and $8 \mathrm{~GB}$ main memory running the Windows 10 operating system. 360 seconds are given for each instances. Thus, each instance group has a total time of 3600 seconds. If the optimum result is reached within 360 seconds, the results of the problems are reported. Otherwise, the best results are reported for the problems that cannot be reached at the end of the given time.

Table 1: Binary variable numbers of both models.

\begin{tabular}{ccccc}
\hline & & Proposed Model & Existing Model \\
\cline { 3 - 5 } Problem \# & Family & Group & Binary Variables & Binary Variables \\
\hline $\mathbf{1}$ & ROSZIEG & $\mathbf{1 , 2 , 3 , 4}$ & 116 & 416 \\
$\mathbf{2}$ & & $\mathbf{5 , 6 , 7 , 8}$ & 186 & 936 \\
$\mathbf{3}$ & HESKIEA & $\mathbf{1 , 2 , 3 , 4}$ & 128 & 464 \\
$\mathbf{4}$ & & $\mathbf{5 , 6 , 7 , 8}$ & 245 & 1421 \\
$\mathbf{5}$ & TONGE & $\mathbf{1 , 2 , 3 , 4}$ & 800 & 7100 \\
$\mathbf{6}$ & & $\mathbf{5 , 6 , 7 , 8}$ & 1479 & 20519 \\
$\mathbf{7}$ & WEE-MAG & $\mathbf{1 , 2 , 3 , 4}$ & 946 & 9196 \\
$\mathbf{8}$ & & $\mathbf{5 , 6 , 7 , 8}$ & 1786 & 27436 \\
\hline
\end{tabular}


As seen in Table 1, existing model has more binary variables than proposed model with the ratio of $91,57 \%$. In Figure-1, binary variable numbers of both model is showed as a graph. Existing model's binary variable number is showed with red and proposed model is showed with blue lines. Also, when we examine the graphical display of the binary variable of both models, it is clear that binary variable ratio have a tendency to increase in existing model. But in the proposed model increasing trend of binary variables are less than 1/4 times when comparing the existing model.

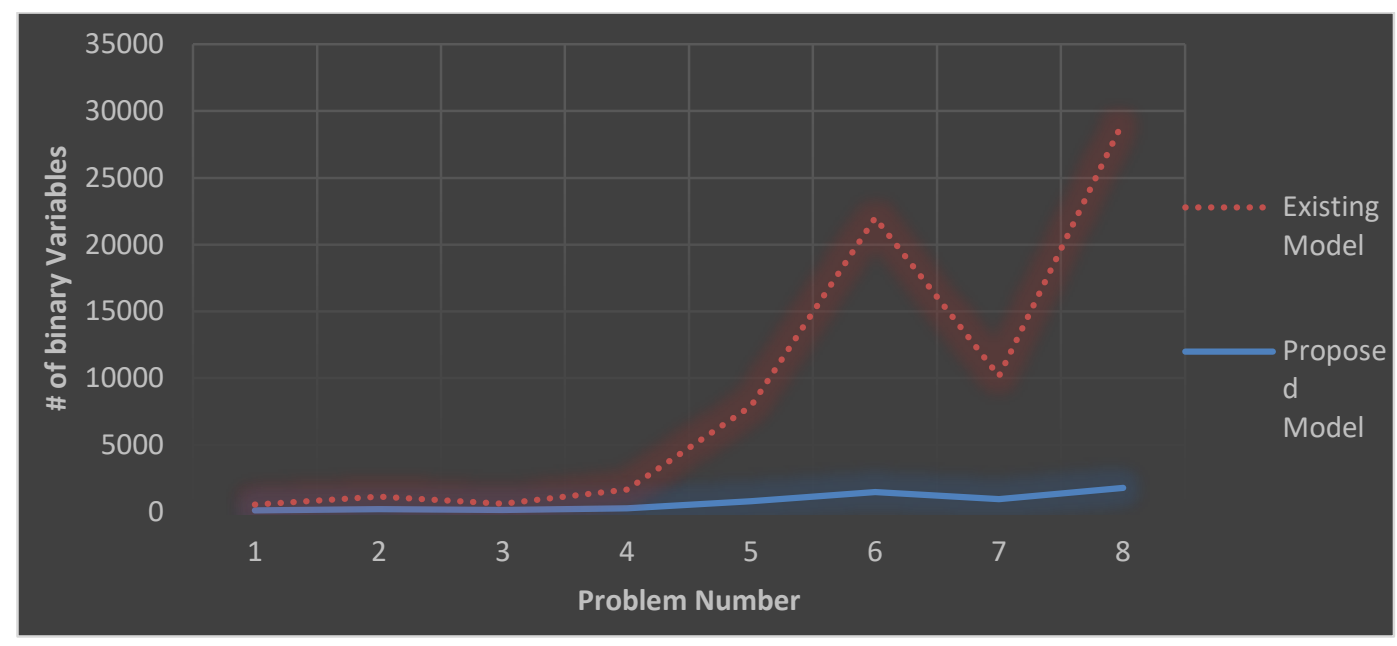

Figure 1. Graphical display of binary variables.

In Table 2, the first and second column represents the test problem family name and group number of the family respectively. Each test problem family group consists of 10 instances. Therefore, cycle time shows the average results of ten instances. The task numbers of Roszieg, Heskiea, Tonge and Wee-Mag is 25, 28, 70 and 75, respectively. Roszieg and Heskiea are small sized test instances in the literature. For this reason, in both problems, the best result was reached without exceeding the time given. The table have 2 main areas, one of them is existing model and the other one is proposed model data. Solution data columns represent cycle time, gap (\%) and CPU times respectively. According to Tables 2, the results show that proposed new mathematical model is superior to the existing model.
Test problem solutions indicate the findings listed below:

- Better results are obtained for $50 \%$ of the 320 test instances in terms of cycle time and 81.25 in terms of CPU time for the problem.

- Also, optimum solutions are found by the proposed model as existing model for the Roszieg and Heskiea test problem family.

- For the Tonge family, our mathematical model finds an optimal solution in second group. In fact, existing model cannot.

- In all Tonge and Wee-Mag family, proposed mathematical model find better solutions than existing model in less time.

- It is stated that proposed mathematical model performs better solutions with less CPU time.

- When we compare the average cycle time of both model, once again proposed model creates better solutions with the ratio of $10.28 \%$ 
Table 2. Comparison of proposed and existing model.

\begin{tabular}{|c|c|c|c|c|c|c|c|}
\hline \multirow[b]{2}{*}{ Family } & \multirow[b]{2}{*}{ Group } & \multicolumn{3}{|c|}{ Existing Model } & \multicolumn{3}{|c|}{ Proposed Model } \\
\hline & & Cycle Time & Gap \% & CPU & Cycle Time & Gap \% & CPU \\
\hline \multirow[t]{8}{*}{ ROSZIEG } & 1 & 20.10 & 0.00 & 0.20 & 20.10 & 0.00 & 0.12 \\
\hline & 2 & 31.50 & 0.00 & 0.16 & 31.50 & 0.00 & 0.09 \\
\hline & 3 & 28.10 & 0.00 & 0.27 & 28.10 & 0.00 & 0.12 \\
\hline & 4 & 28.00 & 0.00 & 0.26 & 28.00 & 0.00 & 0.12 \\
\hline & 5 & 9.70 & 0.00 & 2.58 & 9.70 & 0.00 & 3.69 \\
\hline & 6 & 11.00 & 0.00 & 2.70 & 11.00 & 0.00 & 2.41 \\
\hline & 7 & 16.00 & 0.00 & 4.76 & 16.00 & 0.00 & 6.97 \\
\hline & 8 & 15.10 & 0.00 & 2.74 & 15.10 & 0.00 & 5.48 \\
\hline \multirow[t]{8}{*}{ HESKIEA } & 1 & 102.30 & 0.00 & 0.37 & 102.30 & 0.00 & 0.19 \\
\hline & 2 & 122.60 & 0.00 & 0.34 & 122.60 & 0.00 & 0.16 \\
\hline & 3 & 172.50 & 0.00 & 0.41 & 172.50 & 0.00 & 0.21 \\
\hline & 4 & 171.20 & 0.00 & 0.39 & 171.20 & 0.00 & 0.23 \\
\hline & 5 & 34.90 & 0.00 & 7.72 & 34.90 & 0.00 & 7.68 \\
\hline & 6 & 42.60 & 0.00 & 4.51 & 42.60 & 0.00 & 6.73 \\
\hline & 7 & 75.20 & 0.00 & 4.69 & 75.20 & 0.00 & 5.62 \\
\hline & 8 & 67.20 & 0.00 & 5.95 & 67.20 & 0.00 & 8.44 \\
\hline \multirow[t]{8}{*}{ TONGE } & 1 & 98.10 & 50.37 & 352.14 & 90.90 & 46.44 & 252.68 \\
\hline & 2 & 112.20 & 53.25 & 339.72 & 106.70 & 0.00 & 129.63 \\
\hline & 3 & 171.60 & 62.24 & 360.00 & 160.20 & 59.55 & 289.13 \\
\hline & 4 & 171.60 & 57.58 & 360.00 & 164.40 & 55.72 & 224.54 \\
\hline & 5 & 59.60 & 85.47 & 360.00 & 37.10 & 76.66 & 360.00 \\
\hline & 6 & 67.40 & 77.98 & 360.00 & 40.80 & 63.62 & 352.19 \\
\hline & 7 & 114.80 & 80.39 & 360.00 & 72.50 & 68.95 & 325.16 \\
\hline & 8 & 108.50 & 78.72 & 360.00 & 70.10 & 67.06 & 360.00 \\
\hline \multirow[t]{8}{*}{ WEE-MAG } & 1 & 34.10 & 84.31 & 360.00 & 30.00 & 82.17 & 360.00 \\
\hline & 2 & 39.20 & 81.95 & 360.00 & 35.10 & 79.84 & 360.00 \\
\hline & 3 & 56.00 & 70.83 & 360.00 & 53.70 & 69.58 & 360.00 \\
\hline & 4 & 55.10 & 75.24 & 360.00 & 51.50 & 73.51 & 360.00 \\
\hline & 5 & 21.00 & 90.32 & 360.00 & 13.30 & 84.72 & 360.00 \\
\hline & 6 & 20.20 & 90.00 & 360.00 & 15.30 & 86.80 & 360.00 \\
\hline & 7 & 28.90 & 83.02 & 360.00 & 23.60 & 79.21 & 360.00 \\
\hline & 8 & 28.00 & 81.39 & 360.00 & 22.10 & 76.42 & 360.00 \\
\hline \multicolumn{2}{|c|}{ MEAN } & 66.70 & 37.60 & 281.56 & 60.48 & 33.45 & 163.17 \\
\hline
\end{tabular}

\section{CONCLUSION}

Assembly line worker assignment and balancing problem is a decision making problem that choosing the workers for assembly lines and assigns the tasks to workers. This problem is different from the well-known simple assembly line balancing problem from the view point of task execution times of nonhomogeneous workers. In this paper, we introduced a new mathematical formulation for ALWABP with an objective of cycle time minimization. The best result was reached without exceeding the time given in Roszieg and Heskiea test instances. Also, because of the precedence diagram of test instances, many different binary values were observed. It was found that precedence diagram and complexity of the tests instances play a 
critical role on the performance of the mathematical model. Experimental results showed that our proposed mathematical model outperforms existing model in the literature.

Possible future research directions; proposed problem could be extended with line configurations (stochastic task time, Ushaped,etc).

\section{REFERENCES}

Akyol SD, Baykasoğlu A, 2019. ErgoALWABP: a multiple-rule based constructive randomized search algorithm for solving assembly line worker assignment and balancing problem under ergonomic risk factors. Journal of Intelligence Manufacturing. 30: 291-302.

Battaia O, Dolgui A, 2013. A taxonomy of line balancing problems and their solution approaches. International Journal of Production Economics. 142: 259-277.

Becker C, Scholl A, 2006. A survey on problems and methods in generalized assembly line balancing. European Journal of Operations Research.168: 694-715.

Blum C, Miralles C, 2011. On solving the assembly line worker assignment and balancing problem via beam search. Computers and Operations Research. 38(1): 328-39.

Chaves AA, Miralles C, Lorena LAN, 2007. Clustering search approach for the assembly line worker assignment and balancing problem. 37 th international conference on computers and industrial engineering, 20-23 October 2007, Alexandria, Egypt.

Chaves AA, Lorena LAN, Miralles C, 2009. Hybrid metaheuristic for the assembly line worker assignment and balancing problem. Lecture Notes in Computer Science. 5818: 1-14.
Miralles C, Garcia-Sabater JP, Andres C, Cardos M, 2007. Advantages of assembly lines in sheltered work centers for disabled A case study. International Journal of Production Economics. 110(1): 187-197.

Miralles C, Garcia-Sabater JP, Andres C, Cardos M, 2008. Branch and bound procedures for solving the assembly line worker assignment and balancing problem: Application to sheltered work centers for disabled. Discrete Applied Mathematics. 156(3): 352-367.

Moreira MCO, Costa AM, 2009. A minimalist yet efficient tabu search for balancing assembly lines with disabled workers. Anaisdo XLI Simposio Brasileiro de Pesquisa Operacional, 1-4 September 2009, Porto Seguro, Brazil.

Moreira M, Ritt M, Costa A, Chaves A, 2012. Simple heuristics for the assembly line worker assignment and balancing problem. Journal of Heuristics. 18: 505-524.

Mutlu O, Polat O, Supciller A, 2013. An iterative genetic algorithm for the assembly line worker assignment and balancing problem of type-II. Computers and Operations Research. 40: 418426.

Pereira J, 2018. The robust (minmax regret) assembly line worker assignment and balancing problem. Computers and Operations Research. 93: 2740.

Polat 0, Kalayci CB, Mutlu Ö, Gupta SM, 2016. A two-phase variable neighbourhood search algorithm for assembly line worker assignment and balancing problem type-II: an industrial case study. International Journal of Production Research. 54:3, 722-741.

Vilà M, Pereira J, 2014. A branch-and-bound algorithm for assembly line worker assignment and balancing problems. Computers and Operations Research. 44: 105-114. 